module of the Apollo spacecraft system (8). The propulsion and reaction control systems in this vehicle comprise 1046 joints in stainless steel tubing (3/16 to 2 in diameter, 0.016 to 0.057 in wall thickness) carrying fuel, oxidiser $\left(\mathrm{N}_{2} \mathrm{O}_{4}\right)$ and helium at pressures of up to $3000 \mathrm{psi}$. The gold-nickel alloy is used because of its resistance to $\mathrm{N}_{2} \mathrm{O}_{4}$; the brazing is done with a portable clamp-on induction coil under an inert gas shield.

The same alloy is one of three filler materials used in the brazing of the thrust chamber of the F-l engine powering the first-stage Saturn $V$ launch vehicle of the Apollo spacecraft system (9). Each thrust chamber, which must be fabricated to exceptionally high reliability standards, has 178 primary tubes and 356 secondary tubes and is constructed mainly of a high-temperature nickel alloy (Inconel X-750). The joints are made by a three-step furnace brazing process.

When complete freedom from oxidation is required in addition to all the useful characteristics of gold-nickel alloys, gold-palladium alloys can be used. These materials, some of which have relatively high melting points (up to $1400^{\circ} \mathrm{C}$ ), and gold-palladiumnickel alloys are often found useful in the first (i.e., high-temperature) stages of step-by-step brazing.

Detailed published information on the performance of joints made with gold brazing alloys in various structural materials for service in a wide range of working media and under diverse conditions of stress and temperature is unfortunately scarce. Nevertheless, the few applications described in this article show quite clearly the importance, the present scope and the potential future uses of materials of this kind.

\section{References}

1 D. Fishlock, "Precious Metal Brazing Makes Better Magnetrons", Metalworking Prod., 1961, 105, 49-53

2 Anon., "Special Purpose Brazing Alloys", Metallurgia, $1961,63,(3), 142-144$

3 E. E. Hoffman, P. Patriarca, C. F. Leitten and G. M. Slaughter, "An Evaluation of the Corrosion and Oxidation Resistance of High Temperature Brazing Alloys", ORNL Rept. UC-25, 1956

4 W. H. Chang, "Basic Characteristics of Some Heatresisting Brazing Filler Materials", Welding $\mathscr{F} ., 1956,35$, (9), 431s-443s; "Further Evaluation of $\mathrm{Ni}-\mathrm{Cr}-\mathrm{B}$ and Au-18 Ni Brazing Alloys", Ibid., 1958, 37, (12), 535s-542s

5 M. H. Sloboda, "Design and Strength of Brazed Joints", Welding \& Metal Fab., 1961, 29, (7), 291-296

$6 \mathrm{~J}$. Kolbus and W. Hauch, "Beitrag zum Verhalten von Lötverbindungen aus Hochtamperaturloten auf Edelmetallbasis an hochwarmfesten Werkstoffen bei Zeitstands-Belastungen bis 1000 Stunden und Temperaturen bis zu 800 Grad C", Metall, 1969, 23, (10), 994-1002

7 Johnson Matthey, British Patent Application 39805/68

8 S. J. Whalen, "Aerospace Brazing", Welding Eng., 1968, 53, (3), 62-63

9 F. X. De Carlo, "Brazing Gives Apollo a Lift", $A m$. Machinist, 1967, 111, (15, July 17th), 84-87

\title{
Gold in Electronic Engineering
}

\section{THE INTER-NEPCON CONFERENGE AND EXHIBITION}

World consumption of gold in the electronics industry is now around 100 tons a year and is rising. This usage is, of course, scattered throughout many hundreds of companies operating in this rapidly growing field, but an unusual opportunity to appreciate the major importance of gold in both European and American techniques of electronic circuit design and production was presented at the "Inter-Nepcon 70 " held at Brighton in October. This combination of conference and exhibition, organised by the American journal Electronic Packaging and Production Magazine, attracted over thirteen thousand engineers and more than three hundred exhibitors.

The conspicuous role of gold, both in the papers presented and in the exhibits on view, concerned two distinct groups of components, the many types of contacts and connectors on the one hand and thick film circuits on the other. Increasing requirements of yield, reliability, and long life, combined with the smaller contact pressures available in miniaturised components, have led to the widespread use of gold as a contact material. Electroplating provides the answer in a great number of cases, and electrolytes of many kinds are available to provide high purity or alloyed gold deposits of good ductility and low porosity for contacts, edge connectors for printed circuit boards, semi-conductor devices and other electronic assemblies. In addition to conventional methods of electroplating, the use of continuously or selectively gold plated base metal strip from which parts can readily be produced is clearly becoming of importance. For more critical applications, metallurgically bonded gold inlays in base metal strip can similarly be formed into contacts or connectors. All these products were well represented in the exhibition, while a number of papers dealt with the problems of achieving operational reliability in goldsurfaced contacts and connectors when devices are so small that only very low contact pressures are available.

In the production of integrated and hybrid thick film circuits the individual components are produced by screen printing and firing on to a ceramic substrate a preparation containing one or more of the noble metals dispersed with a powdered glaze or frit in an organic medium. A wide range of gold-bearing preparations of this type is now available from several manufacturers, and these, together with appropriate screen printing machines and specialised furnaces for carrying out the carefully controlled firing operations were exhibited, while a number of papers and open discussions at the conference dealt with considerations of the selection of these materials and their processing into finished circuits. 